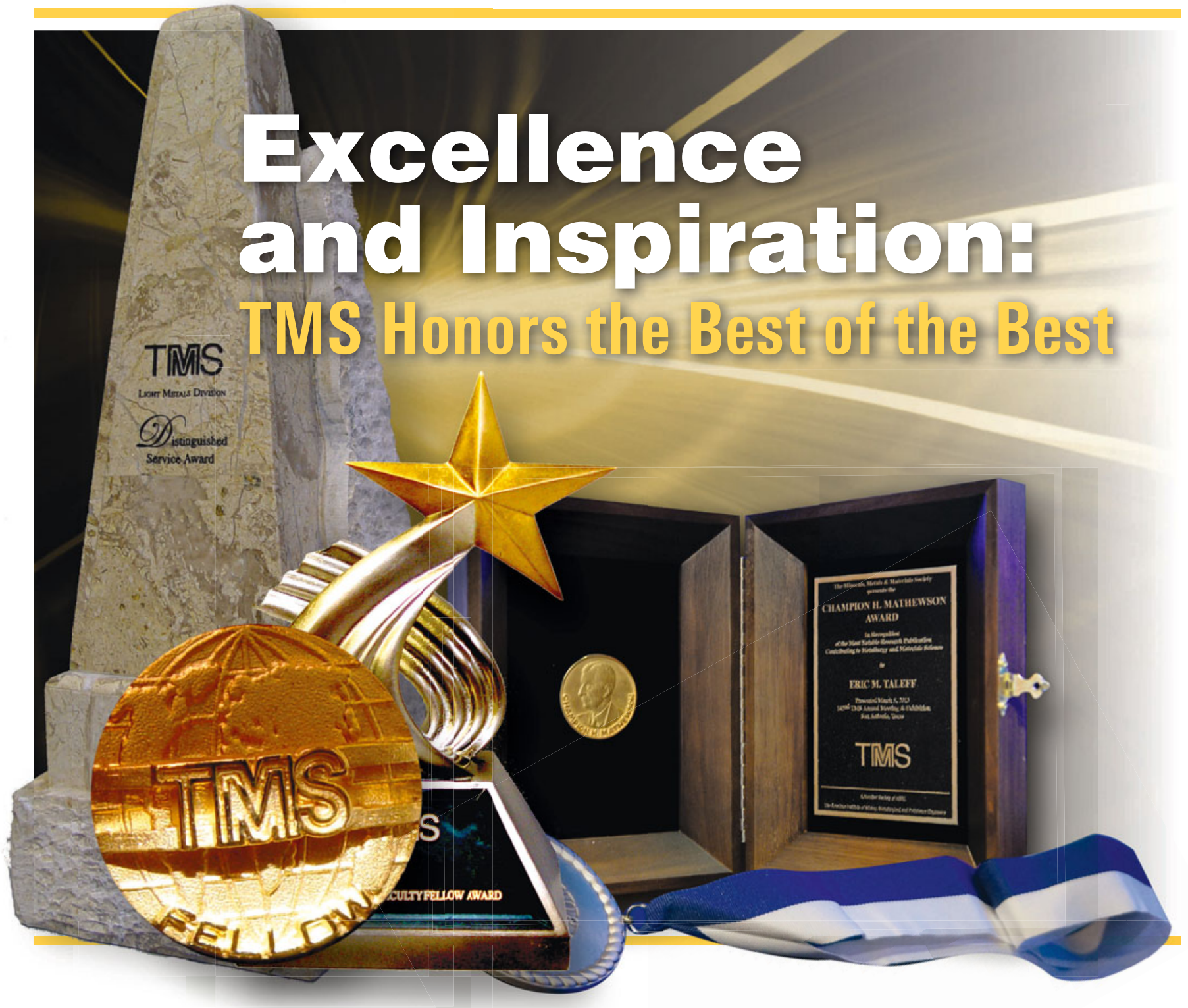

The outpouring of great work and generous exchange of ideas that takes place during a TMS Annual Meeting and Exhibition are the very qualities that make the minerals, metals, and materials professions so vital to the continued advancement of society. That's why recognizing those TMS members who have distinguished themselves from a field of excellence is a focal point of every TMS Annual Meeting.

TMS is further underscoring the significance of its highest professional honors by opening the TMS-AIME Honors and Awards Ceremony to all attendees of the TMS 2014 Annual Meeting \& Exhibition (TMS2014) in San Diego. The program will take place on Tuesday, February 18 , and offers the rare opportunity to see and hear some of the most influential figures in the field at the pinnacle of their careers. This year's ceremony will also be hosted by some of TMS's most esteemed members. Ray Peterson, 2009 TMS President, will present the awards celebrating the achievements of TMS's young and mid-career members. Tresa Pollock, the 2005 TMS President and 2009 TMS Fellow, will honor those receiving TMS's pinnacle awards. And, Carolyn Hansson, 1997 TMS Fellow, will present the 2014 Class of TMS Fellows.

Said Elizabeth Holm, 2013 TMS President on the changes to this year's awards ceremony, "For our more senior members, we believe it will offer a memorable, moving occasion to celebrate the excellence of their colleagues. We hope members early in their careers will take advantage of this chance to congratulate mentors and be inspired to strive for similar heights themselves."

Please join TMS and its divisions in congratulating the following members who will be be honored for their achievements and professional contributions at TMS2014. To learn more about this and other TMS2014 events and activities, visit the TMS2014 website at www.tms.org ttms2014. 


\section{SOCIETY AWARDS}

\section{TMS Fellows}

The class of Fellow is the highest honor bestowed by TMS. To be inducted, a candidate must be recognized as an eminent authority and contributor within the broad field of materials science and technology, with a strong consideration for outstanding service to the Society. The maximum number of living Fellows cannot exceed 100.

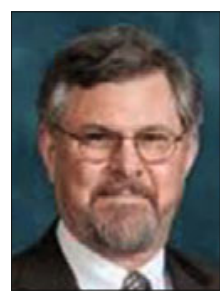

John Allison Professor, University of Michigan Citation: For pioneering achievements and leadership in development of Integrated Computational Materials Engineering methodologies and contributions to understanding the influence of microstructure on properties of metals. "I have been a TMS member for more than 30 years, and TMS is much more than a professional society to me-it is my professional family," said Allison. "TMS meetings and members have been a continual source of inspiration, new ideas, energy, and friendships. I have benefited immensely from this community and I am humbled to be recognized in this way by TMS."

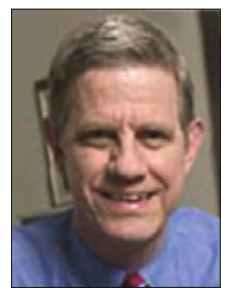

Kevin Hemker

Professor and Chair, Department of Mechanical Engineering, Johns Hopkins University

Citation: For discoveries that govern the mechanical behavior of nanocrystalline, micro-lattice, thermal barrier, and hightemperature materials based on underlying atomic scale processes.

"I first met my Ph.D. advisor, Bill Nix, at a TMS symposium on the 50th anniversary of dislocations in Detroit in 1984, and have been a TMS member ever since," said Hemker. "I have enjoyed rich interactions with colleagues in countless symposia, hallways, committees, and social events. The list of TMS Fellows reads like a 'who's who' of materials scientists and engineers. I have been blessed with the opportunity to get to know and be mentored by many of these giants, and I am humbled to be recognized by TMS for this award."

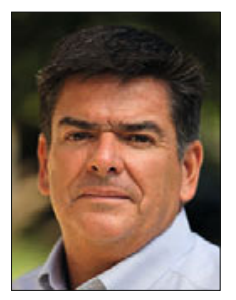

Enrique Lavernia

Dean and Distinguished Professor, University of California, Davis Citation: For his outstanding contributions to the development of novel metal processing techniques and leadership in academic administration.
"I have been a TMS member for many years, first joining the society as a brand-new graduate student in the 1980s at the Massachusetts Institute of Technology (MIT). Since those early years, TMS has been an integral part of my academic life, and has provided me with numerous and important professional opportunities, as well as many lifelong friendships," said Lavernia. "I am extremely humbled by being elected as a TMS Fellow and would like to give credit to many students (both graduate and undergraduates), postdoctoral scientists, staff, colleagues, and mentors with whom I have had the privilege of working."

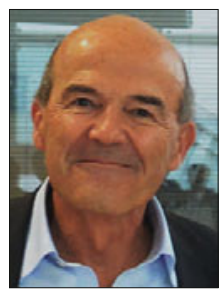

\section{Michel Rappaz}

Professor, École Polytechnique Fédérale de Lausanne

Citation: For sustained, innovative contributions to the fundamental science and practical application of solidification research.

"Knowing the very limited number of fellows nominated by TMS, this is certainly a great honor for me to join this group of distinguished scientists. After receiving the Federation of European Materials Societies (FEMS) Gold Medal in 2013, this TMS award is a recognition of my activity in the field of solidification on the other side of the Atlantic," said Rappaz. "Since my post-doc at Oak Ridge National Laboratory, I have always had a special relationship with the North American materials community. I thank Jon Dantzig, my nominator, colleague, and friend, as well as the other scientists who have supported my candidacy."

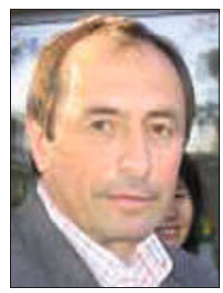

Ruslan Z. Valiev Professor, UFA State Aviation Technical University

Citation: For pioneering works in the processing, fundamental study, innovation, and application of ultrafine-grained and nanostructured materials produced by

severe plastic deformation.

"TMS significantly coordinates research efforts among scientists all over the world, especially its meetings being a platform for the exchange of ideas and information relating to all aspects of materials science," said Valiev. "It gives the opportunity to bring fundamental investigations from laboratory scale to practical application in various branches of industry; it attracts young scientists to modern science; it enables us to share practice, knowledge, and experience; and it duly recognizes achievements with its various awards and interesting publication opportunities. I am proud to be part of it." 


\section{SOCIETY AWARDS}

\section{Alexander Scott Distinguished Service Award}

Recognizing a member's outstanding contributions to TMS, this award is typically presented for 10 or more years of TMS service in membership development, student chapters, education and professional affairs, and/or other societylevel activities.

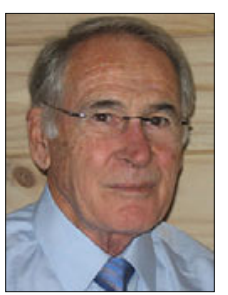

\section{Barry Welch}

\section{Retired, Welbank Consulting}

Citation: For his prolonged and valuable role in promoting the objectives and the international character of TMS by serving on Foundation and other committees, establishing prizes, teaching TMS international courses, and editorial roles including leading the technical side of the first CD-ROM edition of the conference proceedings.

"TMS is, and always will be, a U.S.-based professional society, but it has also been the global center for meetings and information exchange between researchers and practitioners in the light metals industries," said Welch.

"This has made it important for us international members to reciprocate and contribute to maintaining the efficiency and timeliness of the organization."

\section{Application to Practice Award}

Recognizes an individual who has demonstrated outstanding achievement in transferring research results or findings into commercial production and practical use.

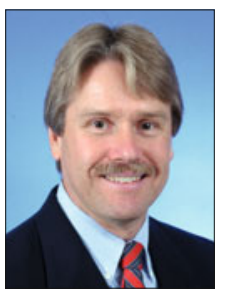

\section{Iver Anderson}

Senior Metallurgist, Ames Laboratory Citation: For seminal contributions in the fundamental understanding, engineering development, and technology transition of alloy development and gas atomization of powder metals. The broad application of his expertise has enabled development in many materials systems including: lead free solders, light metals, magnetic materials, high-temperature materials, energy storage, and magneto-caloric materials. His perseverance from research and development through commercialization demonstrates the beneficial impact a dedicated materials scientist has on society.

"I am very grateful and honored to receive this high honor from my peers in TMS," said Anderson. "All of my former students, colleagues, and collaborators over the years know that my central focus is the use of scientific discovery to solve problems that enable new pathways to making useful materials that can promote benefits to our society."

\section{Brimacombe Medalists}

The intent of this award is to recognize professionals in the middle portions of their careers. It is presented to individuals with sustained excellence and achievement in business, technology, education, public policy, or science related to materials science and engineering.

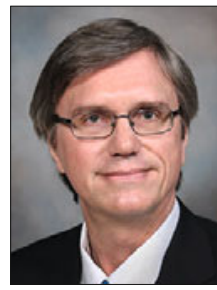

\section{Louis G. Hector} Technical Fellow, General Motors Research and Development Citation: His notable achievements include using computations and experiments to advance our understanding of materials for energy storage and of the performance of structural materials.

"The late Professor Keith Brimacombe led others by example through his boundless commitment to theory and experiment in metallurgical process science. He had no fear of working in manufacturing environments to gain greater understanding of metallurgical processes and devoted substantial energy to the creation of productive partnerships between academia and industry," said Hector. "I am especially honored for the responsibility that I see as a Brimacombe medalist, not only in my service to TMS, but also in my commitment to serving as a role model and mentor for younger scientists and engineers."

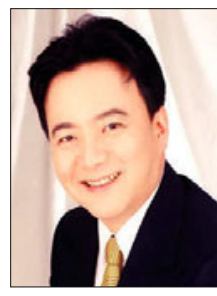

\section{Robert Kao}

Professor, National Taiwan University

Citation: For his outstanding and sustained contributions to the understanding of phase equilibria and interfacial reactions in electronic packaging and interconnect materials.

"I attended my first TMS meeting as a graduate student in 1993, when Professor Brimacombe was the TMS President. To receive this award 20 years later is so very humbling," said Kao. "Nowadays, I attend the TMS meeting every year, always accompanied by several of my own students. I want my students to experience the same professional growth that I gained through my activities with TMS."

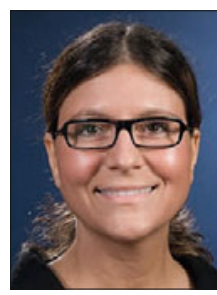

Diana Lados Associate Professor, Worcester Polytechnic Institute Citation: For developing and implementing a new integrative design paradigm in materials science and engineering research, education, and application, and for impactful service to TMS.

"TMS has played, for more than a decade, a major part in my professional and personal development." said Lados. "I enthusiastically look forward to continuing to play an 


\section{SOCIETY AWARDS}

active role and bring my contributions to TMS through my research in materials design integration, organizing symposia, participating in committees, and supporting new activities that will ensure a great future for our society."

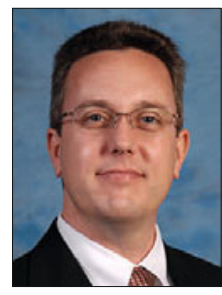

Eric M. Taleff

Professor and Charlotte Maer Patton

Centennial Fellow in Engineering, University of Texas at Austin Citation: For seminal contributions to elevated temperature plasticity, strong commitment to education, and outstanding

service to TMS.

"Professor J. Keith Brimacombe left us a legacy of exceptional education and research that tied academia together with industry, a mission I enthusiastically endorse as aptly supported by TMS," said Taleff. "I welcome the responsibility to continue that mission. It is with eager anticipation that I look forward to many more years of working together with my fellow members to so advance our profession, for this is the means by which we better our larger world."

\section{Bruce Chalmers Award}

This award recognizes an individual who has made outstanding contributions to the science and/or technology of materials processing.

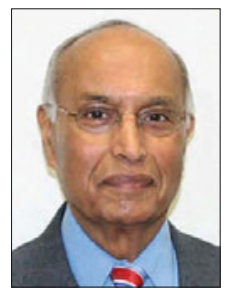

\section{Pradeep K. Rohatgi} Distinguished Professor, University of Wisconsin-Milwaukee

Citation: For internationally recognized leadership in research on solidification processing of metal-matrix composites, which stimulated worldwide research, technology development, manufacture, and use by industry. "Bruce Chalmers was one of the leaders in solidification and I had the privilege of being advised by him on several aspects of my thesis on solidification while I was at MIT," said Rohatgi. "I have had the privilege of extending the basic concepts of solidification developed by Bruce Chalmers to solidification synthesis and processing of metal-matrix composites, syntactic foams, and self-healing materials. TMS has been a great facilitator in my research through its networking opportunities and information base."

\section{Cyril Stanley Smith Award}

Recognizes an individual who has made outstanding contributions to the science and/or technology of materials structure.

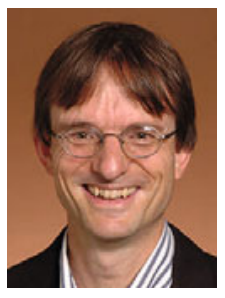

Anthony Rollett Professor, Carnegie Mellon University Citation: For insights into grain growth and texture development derived from quantitative, mesoscale, computer modeling using anisotropic grain boundary properties.

"This award is particularly significant to me because I have been interested in microstructure all my career," said Rollett. "Accordingly, Cyril Stanley Smith was always one of my heroes because his ideas were so seminal in the field."

\section{Early Career Faculty Fellow Award}

Honors an assistant professor for accomplishments that have advanced the academic institution where employed, and recognizes his or her abilities to broaden the technological profile of TMS.

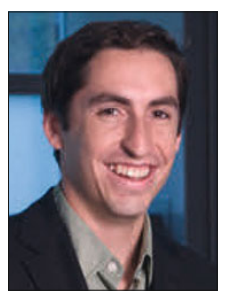

Daniel Gianola Assistant Professor, University of Pennsylvania:

"TMS has always been a great home for materials researchers like me who are looking to make a long-lasting and sustained impact in the field, and I feel proud to be a TMS member," said Gianola. "I'm truly appreciative of this recognition, which gives me a renewed sense of vigor for the wonderful field of materials science and engineering."

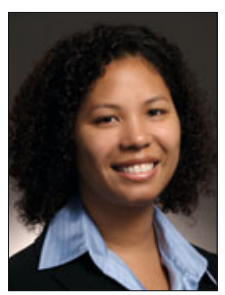

\section{Michele Manuel}

Assistant Professor, University of Florida "I am honored by the fact that my peers have recognized my potential," said Manuel. "Important milestones in a successful career often depend on people who see the promise in you that you sometimes can't see in yourself. This award is a reminder that it's not just you alone who achieve these goals, but a whole community of people who help get you there. To be honored in this way by people I may not even know is astonishing and humbling to me." 


\section{SOCIETY AWARDS}

\section{Educator Award}

Recognizes an individual who has made outstanding contributions to education in metallurgical engineering and/ or materials science and engineering.

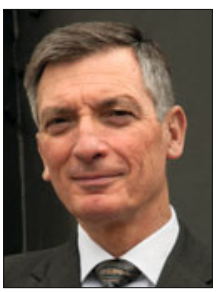

Donald Sadoway

John F. Elliott Professor of Materials Chemistry, Massachusetts Institute of Technology

Citation: For seminal teaching of materials chemistry, kinetics, and electrochemistry to materials science and engineering students and the broader population at large.

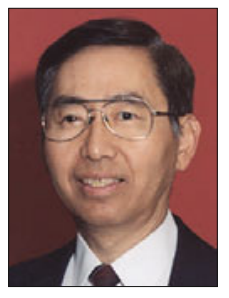

\section{Hong Yong Sohn}

Professor, University of Utah

Citation: For exemplary contributions to metallurgy education through outstanding teaching and mentoring, combined with volumes of scientific research publications that have enhanced the understanding of metallurgical principles and applications for generations of metallurgists.

"The TMS Educator Award has a special meaning because it is a culmination of my teaching career in its entirety. It is an added bonus to be recognized for doing what I enjoy most doing-Ever since high school, I always wanted to teach," said Sohn. "Membership in TMS has been essential to me in providing a career-long opportunity to exchange ideas and form professional bonds with colleagues of similar technical interests."

\section{Institute of Metals Lecturer \& Robert Franklin Mehl Award}

Recognizes an outstanding scientific leader who is selected to present a lecture at the TMS Annual Meeting.

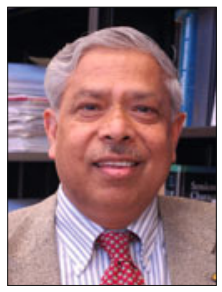

Jagdish Narayan

John C. Fan Distinguished Chair Professor, North Carolina State University

Citation: For seminal contributions in ion implantation and laser processing of novel materials, domain epitaxy across the misfit scale, defects and interfaces, nanostructured materials, and leadership in materials science.

"As I am a great fan of Professor Mehl, this award holds a special significance for me," said Narayan. "As a life member and fellow of TMS, I have been very proudly associated with TMS more than forty years. TMS has served me well with my passion to take materials science and technology to the greater good of the society."

\section{Leadership Award}

Recognizes an individual who has demonstrated outstanding leadership in the national and international materials community in some aspects of the fields of metallurgy and materials.

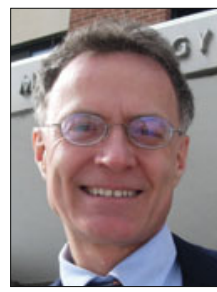

John Lewandowski Arthur P. Armington Professor of Engineering II, Case Western Reserve University

Citation: For being an eminent leader on the fatigue and fracture of materials, with extensive career accomplishments.

\section{Morris Cohen Award}

Recognizes an individual who has made outstanding contributions to the science and/or technology of materials properties.

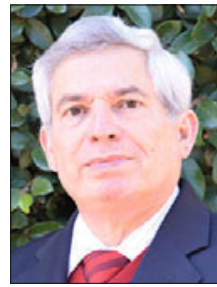

Carlos Levi

Professor, University of California, Santa Barbara

Citation: For outstanding contributions to the understanding of solidification and transformations in Ti-based alloys and ceramic coatings.

"It is an overwhelming and humbling experience to receive an award named after Professor Cohen, one of the most respected and admired scientists in our field, and it is especially meaningful because it comes from TMS, a society that has been a professional home from the early days of my career," said Levi.

\section{Vittorio de Nora Prize for Environmental Improvements in Metallurgical Industries}

Recognizes outstanding materials science research and development contributions to the reduction of environmental impacts as applied in global metallurgical industries, with a particular focus on extractive processing.

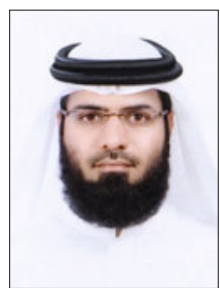
Abdalla Ahmed Al Zarouni Manager, Technology Process Development, Dubai Aluminum Co. Ltd. "In Dubai, we were able to achieve very low PFC emissions compared to the industry average," said Al Zarouni. "Our new high amperage cell technologies equipped with advanced cell controls and strict operational practices are setting the benchmark in PFC emission levels. This award is one of the ways to drive people to work actively on reducing the environmental impact of the industry." 


\section{SOCIETY AWARDS}

\section{William Hume-Rothery Award}

This award recognizes a scientific leader for exceptional scholarly contributions to the science of alloys by inviting $\mathrm{him} /$ her to be an honored presenter at the William HumeRothery Memorial Symposium.

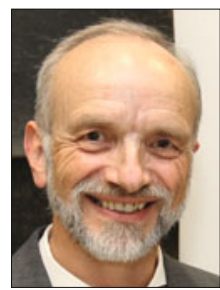

Rainer Schmid-Fetzer, Professor, Clausthal University of Technology Citation: For his seminal contribution in alloy thermodynamics and phase diagrams, both computationally and experimentally.
"I try to follow the great pioneer, Hume-Rothery, in the field of constitution of metals and alloys by elaborating quantitative thermodynamic descriptions of phase stability in truly multicomponent alloys with applications to phase and microstructure formation in processing technology," said Schmid-Fetzer. "I am looking forward to the special symposium in 2014 and to stimulating discussions at the TMS Annual Meeting, which I have enjoyed so many times."

\section{AIME AWARDS}

\section{AIME Champion H. Mathewson Award} Awarded to an author(s) of a paper or series of closely related papers, representing the most notable contribution to metallurgical science during the period under review.

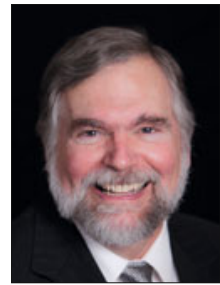

Neal Evans

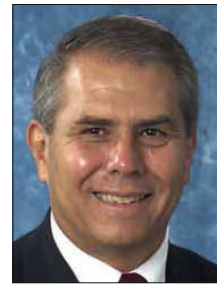

Philip J. Maziasz

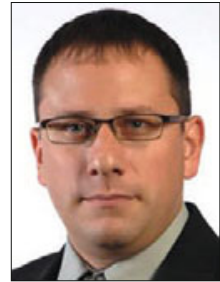

John P. Shingledecker
Neal Evans, Proton Power Inc.; Philip J. Maziasz, Distinguished Research Scientist, Oak Ridge National Laboratory; John P. Shingledecker, Senior Project Manager, Electric Power Research Institute; Michael J. Pollard, Engineering Specialist, Caterpillar Technical Center:

Paper: "Structure and Composition of Nanometer-Sized Nitrides in a Creep-Resistant Cast Austenitic Alloy," Metall. Mater. Trans. A, Vol 41A, December 2010. "What is particularly poignant to me in the nomination of our paper is the recognition of the scientific community that our alloy development, resulting in improved hightemperature properties, had a sound metallurgical basis, and our paper, which described the material microstructure, provided a significant contribution to the materials research community," said Shingledecker. "This paper represents the high point in analytical electron microscopy analysis by Neal Evans to define and characterize the Nb-nanonitride phase present in the cast CF8C-Plus austenitic stainless steel during creep," added Maziasz. Noted Evans, "TMS has been steadfast in providing effective forums and venues for exchanging scientific information relevant to the metallurgical and materials sciences. My participation in society meetings and conferences, as well as my volunteering for service within the society, have both enhanced my professional development and allowed me to participate in the important mission of TMS."

\section{AIME Honorary Membership}

This is awarded in appreciation of outstanding service to or distinguished scientific or engineering achievement in the fields embracing the activities of the American Institute of Mining, Metallurgical, and Petroleum Engineers (AIME) and its member societies.

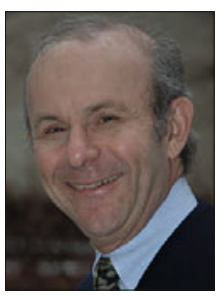

\section{David Seidman}

Walter P. Murphy Professor of Materials Science and Engineering, Northwestern University

Citation: For pioneering seminal research and development of field-ion microscopy and atom-probe tomography to study basic scientific and technological problems in materials science and engineering.

"Much of my research has been presented at the annual TMS meetings, where I have also learned a great deal about materials and their manifold properties and applications during the course of my long professional career," said Seidman. "It has always been and is very gratifying to see my former Ph.D. and postdoctoral students present their research results as their own careers grew and became established." 


\section{AIME AWARDS}

\section{AIME Robert Lansing Hardy Award}

Recognizes outstanding promise for a successful career in the broad field of metallurgy and materials science by a professional under the age of 35 .

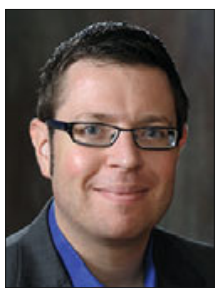

\section{Dallas Trinkle}

Associate Professor, University of Illinois at Urbana-Champaign

Citation: For pioneering use of quantum mechanical calculations to search for chemistry changes that guide the design of improved alloys.

"I am deeply honored to join this prestigious group of top researchers in materials science and engineering. It is an award that speaks to the future of materials science and engineering, as the previous recipients exemplify," said Trinkle. "I am thankful for the mentorship and collegiality of TMS - a society that has been instrumental in my development as a materials science researcher. I would not be where I am today without TMS, and I look forward to many exciting developments in the future of the society as an active member."

\section{ADDITIONAL AWARDS}

\section{Acta Materialia Gold Medal Award}

Recognizes an outstanding contributor to materials science and a leader in materials research.

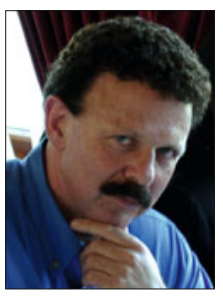

\section{Robert O. Ritchie}

H.T. \& Jessie Chua Distinguished Professor of Engineering, University of California, Berkeley

\section{Acta Materialia Materials \& Society Award} Recognizes outstanding contributions to understanding the relationship between materials technology and society, and/ or contributions to materials technology that have had a major impact on society.

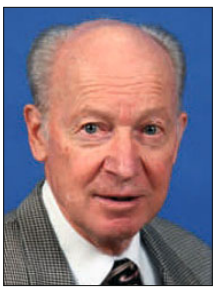

Karl A. Gschneidner, Jr. Anson Marston Distinguished Professor, Iowa State University; Senior Metallurgist, Ames Laboratory, Chief Scientist, U.S. Department of Energy's Critical Materials Institute

\section{AIME James Douglas Gold Medal}

Recognizes distinguished achievement in non-ferrous metallurgy, including both the benefication of ores and the alloying and utilization of non-ferrous metals.

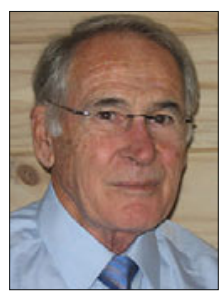

Barry Welch Retired, Welbank Consulting

Citation: For outstanding teaching and research, particularly in the smelting of aluminum, and for significant contributions to the advancement of the aluminum industry.

"While I have been honored by various international academies and professional societies for my research contributions, I consider the receipt of this AIME award to be one of the most important in my life," said Welch. "James Douglas was a man of principle but, more importantly, he placed great emphasis on achieving practical outcomes for the mining and metallurgical industries, as well as making valuable contributions to society. Like James Douglas, achieving useful outcomes has always dominated my professional focus."

\section{DIVISION AWARDS}

\section{Electronic, Magnetic \& Photonic Materials Division (EMPMD) Distinguished Service Award}

Recognizes an individual whose continuous service to the TMS EMPMD has clearly facilitated the society's capability to serve its electronic, magnetic, and photonic materials-oriented members and supporting organizations.

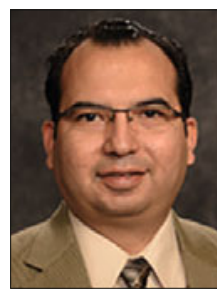

Raymundo Arroyave Associate Professor, Texas A\&M University

Citation: For exemplifying the qualities of leadership within TMS. He has continuously participated and expanded his activities in TMS. This phenomenal dedication and energy makes him one of its most wellversed and most active members.

"I am grateful for this award because TMS is MY society. Since I joined back in 2002, I have only encountered kindness, friendship, and encouragement among my colleagues and the TMS staff," said Arroyave. "I am humbled because whatever I have contributed has been thanks to the encouragement, advice, and example of many colleagues, whose tremendous enthusiasm for-and dedication to - the society is something I hope to emulate." 


\section{DIVISION AWARDS}

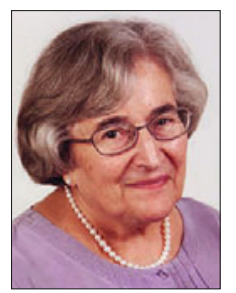

\section{Laura Turbini}

Consultant, International Reliability

Consultants

Citation: For her great passion of student education not only in the classroom, but also at the TMS annual meetings. Her vision and passion can be seen in her activities of volunteer, teacher, and attendee.

"It has been my pleasure to serve TMS for more than 15 years, initially as an ABET evaluator and later as a member of the Electronic Packaging and Interconnect Materials Committee," said Turbini. "In all of these activities, I have been able to reach out to the younger members of the society and to encourage and mentor them. TMS is a wonderful professional society to be a part of, and I am deeply honored to receive this award."

\section{EMPMD Distinguished}

\section{Scientist/Engineer Award}

Recognizes an individual for research excellence in one or more areas related to electronic, magnetic, and photonic materials science.

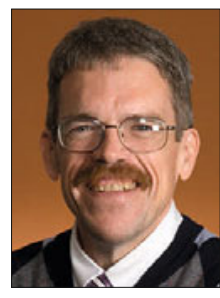

Michael McHenry, Professor, Carnegie Mellon University

Citation: For his outstanding contributions to fundamental understanding of magnetic and superconducting materials and their applications.

Said McHenry, "It has been a pleasure for me to participate in many TMS forums and events over the years. I am pleased to be recognized by my peers."

\section{EMPMD John Bardeen Award}

Recognizes an individual who has made outstanding contributions and is a leader in the field of electronic materials.

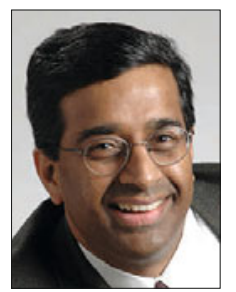

Ramamoorthy Ramesh, Deputy Director, Oak Ridge National Laboratory Citation: For pioneering research in the field of functional oxide materials. "Just being associated with Professor Bardeen's name means a lot to me," said Ramesh. "He epitomized the consummate scientist/engineer, someone who transcended traditional disciplinary boundaries to explore the frontiers of science in the interest of mankind. I hope and aspire to become one like Professor Bardeen.”

\section{Extraction \& Processing Division (EPD) Distinguished Service Award}

Recognizes an individual who has demonstrated outstanding long-term service to industries served by the TMS EPD.

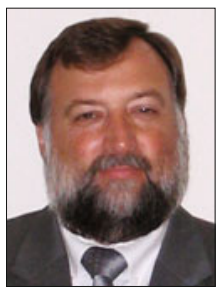

\section{Thomas Battle} Senior Metallurgist, Midrex Technologies Citation: For his outstanding service to TMS and his leadership to the EPD in growing the program and strengthening the involvement of volunteers.

\section{EPD Science Award}

Recognizes a paper that represents notable contributions to the scientific understanding of the extraction and processing of nonferrous materials.

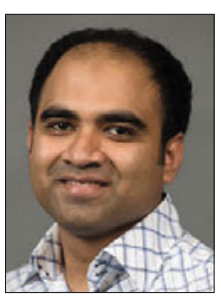

Nazmul Huda

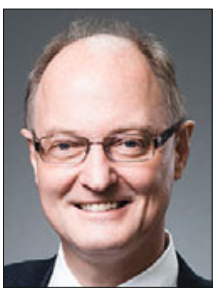

Markus A. Reuter

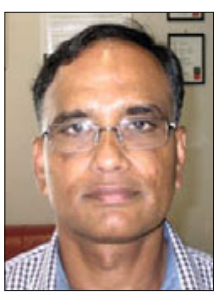

Jamal Naser

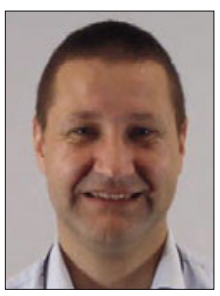

Robert W. Matusewicz

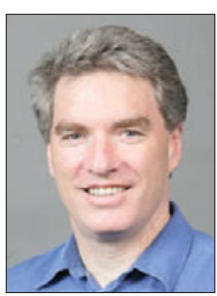

Geoffrey Brooks
Nazmul Huda, Lecturer of Mechanical Engineering, Macquarie University; Jamal Naser, Associate Professor, Swinburne University of Technology; Geoffrey Brooks, Head, High-Temperature Processing Group, Swinburne University of Technology; Markus A. Reuter, Professor, Outotec Oyj, Aalto University; Robert W. Matusewicz, Technical Development Manager-TSL Smelting, Outotec Limited

Paper: "Computational Fluid Dynamic Modeling of Zinc Slag Fuming Process in Top-Submerged Lance Smelting Furnace," Metall. Mater. Trans. B, Vol 43B, Feb. 2012. "Winning this award with colleagues is a great thrill," said Brooks. "The results show that mathematical models can be very useful in describing the details of how pyrometallurgical reactors work." Added Matusewicz, "Most pleasing is that it shows how collaboration between universities and industry can be used effectively to further knowledge and understanding." 


\section{DIVISION AWARDS}

\section{EPD Distinguished Lecture Award}

Recognizes an eminent individual in the field of the extraction and processing of nonferrous metals with an invitation to present a comprehensive lecture at the TMS Annual Meeting.

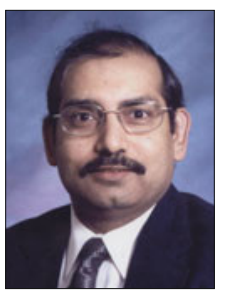

Brajendra Mishra, Professor, Colorado School of Mines

Citation: For his research contributions in the area of resource recovery and recycling of non-ferrous metals for energy minimization, environmental management, and value-added product development. "I am elated that my peers have picked me for this prestigious award, which is the highest recognition that the Extraction \& Processing Division of TMS bestows," said Mishra. "The award will have a special place in my heart as it comes from my home division of my primary professional society of 30 years."

\section{EPD Technology Award}

Recognizes a paper containing notable contributions to the advancement of technology related to the extraction and processing of nonferrous metals.

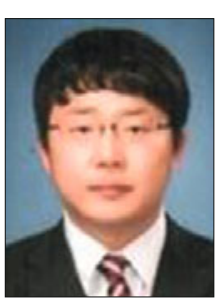

Gwang Seop Lee

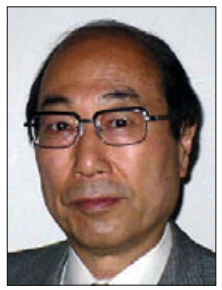

Kouji Mimura

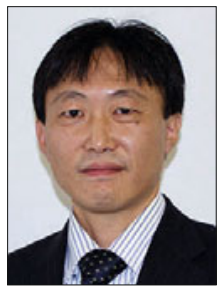

Masahito Uchikoshi

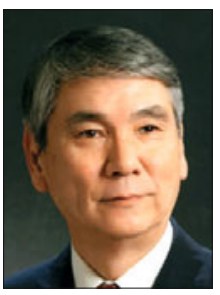

Minoru Isshiki
Gwang Seop Lee, Processing Technology

Team, Korea Resources Corporation; Masahito Uchikoshi, Assistant Professor, Tohoku University; Kouji Mimura, Associate Professor, Tohoku University; Minoru Isshiki, Professor Emeritus, Tohoku University Paper: "Preparation and Evaluation of HighPurity $\mathrm{La}_{2} \mathrm{O}_{3}, "$ Metall.
Mater. Trans. B, Vol 41B, June 2010.

"Although it is the first time for me to receive this award, it gave me great confidence in further devoting myself in my research field such as hydrometallurgy," said Lee. Added Uchikoshi, "This award makes me recognize that purification is still one of the most important areas of metallurgy and motivates me more and more." Mimura also said, "This valuable award will support us to continue further studies concerning the development of some advanced refining/purification methods."

\section{Light Metals Division (LMD) Distinguished Service Award}

Recognizes an individual whose continuous service to the TMS LMD has clearly facilitated the society's capability to serve its light metals-oriented members and their supporting organizations.

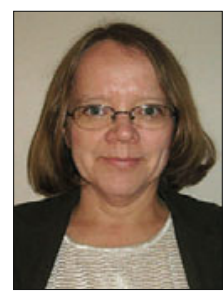

\section{Cynthia Belt}

Energy Management Consultant

Citation: For providing service to the LMD, and the Energy Committee in particular, and her tireless dedication, immeasurable impact, and commitment to fostering communication and cooperation across division boundaries.

Said Belt, "I am honored to receive this award. I want to thank the TMS staff and the LMD and EPD Councils for all their help and encouragement in growing the Energy Committee over the years. Volunteering with TMS has helped me develop both professionally and as a person."

\section{LMD Technology Award}

Recognizes an individual who has demonstrated outstanding long-term service to the light metals industry by consistently providing technical and/or operating knowledge that has enhanced the competitiveness of the industry.

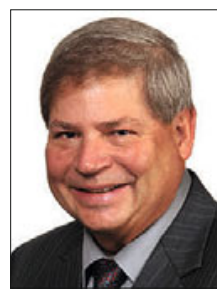

Gary Tarcy Manager, Smelting Research and Development, Alcoa Inc. Citation: For the outstanding applied research of his generation-the measurement of current efficiency. "Although I am honored to have won this award, I feel this is truly an Alcoa team award, because if I had not worked with such fine people and such a great company for 34 years I would not have had the opportunities to win this award," said Tarcy. "TMS also provided me opportunities to meet professionals outside of Alcoa from all over the world whom I have learned from at meetings and by reading their papers." 


\section{DIVISION AWARDS}

\section{LMD JOM Best Paper Award}

Recognizes the author(s) of a paper published in an issue of the preceding year's volume of JOM under a light-metalsrelated technical topic.

Laura Talens Peiró, Research Fellow, INSEAD Europe Campus; Gara Villalba Méndez, Professor, Universitat Autònoma de Barcelona; Robert U. Ayres, Professor Emeritus, INSEAD Europe Campus

Paper: "Lithium: Sources, Production, Uses, and Recovery Outlook," JOM, Vol. 65, August 2013.

\section{Light Metals Award}

Awarded to the author(s) of a paper presented in the preceding year in an LMD-sponsored session at the annual meeting, which notably exemplifies the solution of a practical problem.

Mikhail Lukin, Reduction and Technical Manager, RUSAL Kubikenborg Aluminium AB; Richard Jeltsch, Jeltsch Consulting

Paper: "Reduction Cell Restart Method Influence on Cell Life Evolution."

"The TMS Light Metals proceedings always show high author and editorial professionalism, extreme scientific value, and for the whole my career, were the main source of post-university education, professional inspiration and valuable solutions," said Lukin. "In other words, TMS itself has major contribution in the award that it grants me."

The following Light Metals Subject Awards recognize individual excellence of papers presented the preceding year in a LMD-sponsored session at the Annual Meeting.

\section{Light Metals Subject}

\section{Award-Alumina and Bauxite}

Alexander Senaputra, Ph.D. Candidate, Curtin University; Phillip Fawell, CSIRO; Franca Jones, Senior Lecturer, Curtin University; Peter Smith, CSIRO Paper: "Sodalite Solids Formation at the Surface of Iron Oxide and Its Impact on Flocculation."

"This award means recognition for the quality of the work that I, and my collaborators, have undertaken over the years," said Jones. "It also recognizes the importance of being able to conduct work that is of industrial relevance and has real world applications." Senaputra likewise stated, "This prestigious award is very meaningful as a reflection that my work is well received by the broader scientific communities in the United States."

\section{Light Metals Subject Award-Electrode Technology for Aluminum Production}

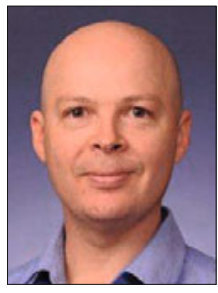

David Molenaar

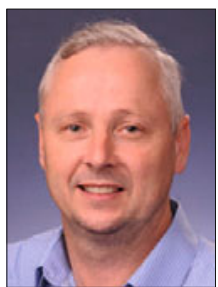

Tony Kilpatrick

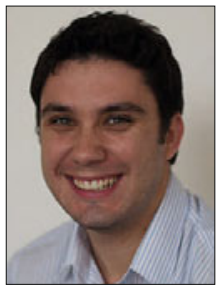

Alex Montalto

David Molenaar, Research Consultant, CSIRO; Tony Kilpatrick, CSIRO; Alex Montalto, Royal Melbourne Institute of Technology University

Paper: "Experimental Investigation of Factors Affecting the Electrical Performance of the Stub to Carbon Connection."

"My team is relatively new to attending and presenting at TMS," said Molenaar. "Recognition by means of this award provides valuable feedback to the team, our supportive management, and our engaging client base that our technical contribution to the sector is of high relevance."

\section{Light Metals Subject Award-Warren Peterson Cast Shop for Aluminum Production}

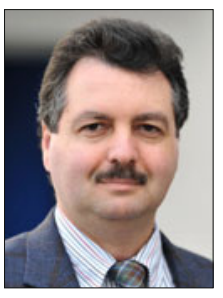

Dmitry Eskin
Dmitry Eskin, Professor, Brunel University; Noe Alba-Baena, Research Fellow, Brunel University Paper: "Kinetics of Ultrasonic Degassing of Aluminum Alloys."

"TMS gives the unique opportunity to communicate the results of research to a large and dedicated community of scientists, engineers and industrialists," said Eskin. "I have a very satisfying feeling, receiving this award, that my research is recognized and well received by the light metals community." Added Alba-Baena, "TMS has been a cornerstone in my development for the last 10 years. This award means a lot because it recognizes the efforts of all in Bcast and ultragassing."

\section{Light Metals Subject Award-Recycling} Byoung-Gi Moon, Senior Researcher, Korea Institute of Materials Science

Paper: "Purification of Highly Contaminated Magnesium Melt." 


\section{DIVISION AWARDS}

\section{LMD Energy Best Paper-Professional}

This award recognizes the author(s) for excellence of a paper published in the preceding year's volume of the energy proceedings or JOM magazine.

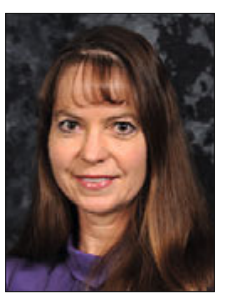

Donna P. Guillen, Distinguished Staff Engineer, Idaho National Laboratory

Paper: "The Autoignition of Cyclopentane in an Ignition Quality Tester," JOM, Vol. 64, May 2012. "It is energizing to be part of the TMS LMD, a highly respected group of professionals from industry, academia, and government working to advance technical knowledge in the materials field," said Guillen. "I look forward to attending the TMS Annual Meeting each year and having the opportunity to interact with this group of professionals. The exchange of ideas and feedback on applying my research to industrial applications has enhanced its value and impact to the materials community."

\section{LMD Energy Best Paper-Student}

This award recognizes the author(s) for excellence of a paper published in the preceding year's volume of the energy proceedings or JOM magazine.

Jarrod D. Milshtein, Graduate Research Assistant, Massachusetts Institute of Technology; Soumendra Basu, Associate Division Head, Boston University; Srianth Gopalan, Associate Professor, Boston University; Uday B. Pal, Professor, Boston University

Paper: "A Thermochemical Study of the $\mathrm{W} / \mathrm{WO}_{3}$ System: A Solar to Fuel Converter for Syngas Production," Energy Technology 2013.

"Since beginning my undergraduate academic career, I have been on a mission to contribute to the field of advanced energy technologies," said Milshtein. "This award is reassurance that I am on the correct path towards a significant impact on the global energy challenge."

\section{LMD Magnesium Technology \\ Best Paper-Application}

Recognizes individual excellence of a paper published in the preceding year's volume of Magnesium Technology on the topic of application to magnesium technology.

Matthias Gieseke, Laser Zentrum Hannover e.V.; Christian Noelke, Laser Zentrum Hannover e.V.; Stefan Kaierle, Laser Zentrum Hannover e.V.; Volker Wesling, Clausthal University of Technology; Heinz Haferkamp, Laser Zentrum Hannover e.V.

Paper: "Selective Laser Melting of Magnesium and Magnesium Alloys."

"This has been unexpected and surprising for me," said
Gieseke. "Because establishing magnesium within the selective laser melting process is in its early stages, I did not expect such great interest in this technology. This fully encourages me to continue my work."

\section{LMD Magnesium Technology Best Paper-Fundamental Research}

Recognizes individual excellence of a paper published in the preceding year's volume of Magnesium Technology on the topic of fundamental research to magnesium technology.

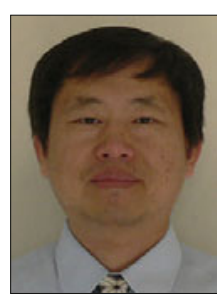

Bin Li

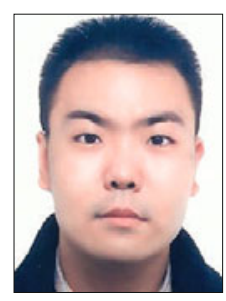

Bo-Yu Liu

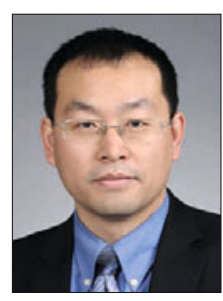

Zhi-Wei Shan
Bin Li, Assistant Research Professor, Mississippi State University; Bo-Yu Liu, Ph.D. Candidate, Xi'an Jiaotong University; Zhi-Wei Shan, Executive Director, Xi'an Jiaotong University

Paper: "Twin Boundary Migration Creating Zero Shear Strain: In-Situ TEM Observations and Atomistic Simulations."

Said Li, "This award typifies a fruitful international collaboration that was created when the authors first met and discussed fundamental issues of magnesium at TMS2012. This award also exemplifies the empowerment of TMS for its highly diversified members around the world." Added Liu, "This award will greatly encourage our further research. We are looking forward to seeing the promised application of our work by taking the advantage of international discussion and collaboration provided by TMS." "It is great to see our recent work on deformation mechanism in magnesium can be recognized," Shan agreed. "It opens a new way to solve the practical problem in the application of magnesium and its alloys."

\section{LMD Magnesium Technology Student Paper}

Recognizes the best paper contributed at the TMS Magnesium Technology Symposium for research/ development work by a student.

Victoria Miller, Graduate Student, University of California; Tresa Pollock, Professor, University of California

Paper: "Recrystallization Behaviour of a MgAlCa Alloy during Thermomechanical Processing and Subsequent Heat Treatment."

"Until only a few years ago, I had been focusing on very 


\section{DIVISION AWARDS}

short-term practical concerns, never mind the underlying science," said Miller. "Conducting research as part of my graduate degree has changed that perspective, and interacting with TMS members has exposed me to numerous career pathways that I had never considered. This award gives me further confidence that I am on the right path."

\section{LMD Magnesium Technology Best Poster}

Recognizes the best contribution to the TMS Magnesium Technology symposium poster session for a research/ development work by an individual or research group. David Fullwod, Associate Professor, Brigham Young University; Michael Miles, Associate Professor, Brigham Young University; Timothy Ruggles, Brigham Young University; Travis Rampton, Brigham Young University; Raja K. Mishra, Staff Research Scientist, General Motors Research Laboratory

Poster: "Resolving Dislocation and Twin Deformation Modes in AZ31."

"This award exemplifies the high quality of research that graduate students can execute when a well-defined industrial problem is taken up for solution by an academic team," said Mishra. "GM collaborated with Brigham Young University (BYU) professors and mentored the students to develop a tool that would be useful for General Motors (GM) to identify formability roadblocks for magnesium usage in automobiles." Added Fullwood, "The work presented in this poster represents the culmination of a stimulating collaboration between BYU and GM in the area of lightweight metals. We are delighted that TMS has chosen to highlight the project's unique combination of microscopy enhancements and experimental developments."

\section{Materials Processing \& Manufacturing Division (MPMD) Distinguished Service} Award

Recognizes an individual whose dedication and commitment to the MPMD has made a demonstrable difference to the objectives and capabilities of the division and TMS.

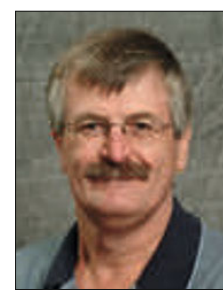

James Sears

Senior Process Engineer-Additive Manufacturing, GE Global Research Center

Citation: For distinguished service to the Materials Processing \& Manufacturing Division of TMS as well as significant contributions in service to other societies in advancing particulate processing of materials.

\section{MPMD Distinguished Scientist/Engineer}

\section{Award}

Recognizes an individual who has made a long-lasting contribution to the design, synthesis, processing, and performance of engineering materials with significant industrial applications.

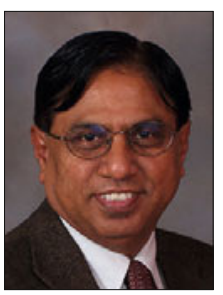

Narendra Dahotre, Distinguished Research Professor and Chair, Materials Science and Engineering, University of North Texas Citation: For pioneering contributions to fundamental understanding and engineering applications of lasermaterials interactions along with implementation of high power lasers in materials processing.

"I have been a member of TMS since the '80s as a graduate student, and gained valuable experiences through involvement and interactions within TMS," said Dahotre. "These experiences and activities have provided opportunities to develop my professional career in the most fulfilled manner."

\section{Structural Materials Division (SMD) Distinguished Service Award}

Recognizes an individual whose dedication and commitment to the SMD has made a demonstrable difference to the objectives and capabilities of the division and the society.

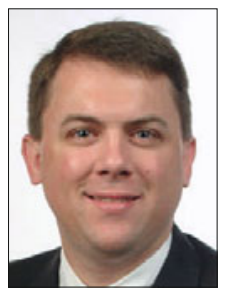

\section{Eric Ott}

Principal Engineer, GE Aviation

"I initially joined as a joint TMS/ASM member during my first year of college. At that time, I recognized TMS primarily as the organization behind the large annual conferences and the monthly JOM magazine. The combination of broad-ranging conference session topics and the technical articles opened my eyes to the many facets of the materials science field as I was trying to learn where my interests would take me," said Ott. "As I advanced further in my education and then onto engineering roles, TMS allowed me to stay connected to the quickly evolving field of materials well beyond what my engineering job focus would allow at the time. Ultimately, it is all about the people. I have found that service in TMS has always rewarded me with an abundance of new opportunities to meet and connect with people and develop new professional ties." 


\section{DIVISION AWARDS}

\section{SMD Distinguished Scientist/Engineer Award}

Recognizes an individual who has made a long-lasting contribution to the fundamental understanding of microstructure, properties, and performance of structural materials for industrial applications.

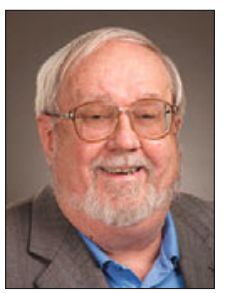

G. Robert Odette, Professor, University of California, Santa Barbara

Citation: For seminal contributions to fundamental understanding of irradiation effects on materials and translation into predictive engineering models of materials performance.

"TMS Annual Meetings are seldom-missed, wonderful events, where I and my research group have been able to exchange ideas, learn about amazing new science, interact with outstanding collaborators and establish new interactions with world leading researchers," said Odette. "Whatever I have been able to accomplish owes a debt to many of these great individuals. The intellectual cross fertilization provided by TMS meetings, as well as by $J O M$, has been very important to me on a personal basis, as well as to our field, one which is so important to scientific and technological progress."

\section{SMD JOM Best Paper Award}

Recognizes the author(s) of a paper published in an issue of the preceding volume year of JOM under a structural materials related technical topic.

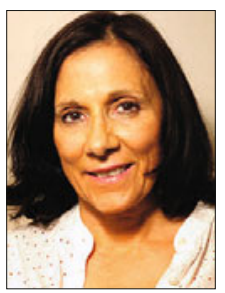

\section{Teresa E. Perez, Engineer, Tenaris} Paper: "Corrosion in the Oil and Gas Industry: An Increasing Challenge for Materials," JOM, Vol. 65, August 2013. "TMS is and has been a key organization promoting actions concerned with metals and materials and $J O M$ is a relevant publication in the field," said Perez. "To receive an award from this institution and during the TMS Annual Meeting is, no doubt, a great honor and a valuable professional recognition."

This article was compiled by Lynne Robinson, JOM Contributing Editor, Taitia Shelow, freelance writer, and Deborah Price, TMS Awards and Recognition Specialist.

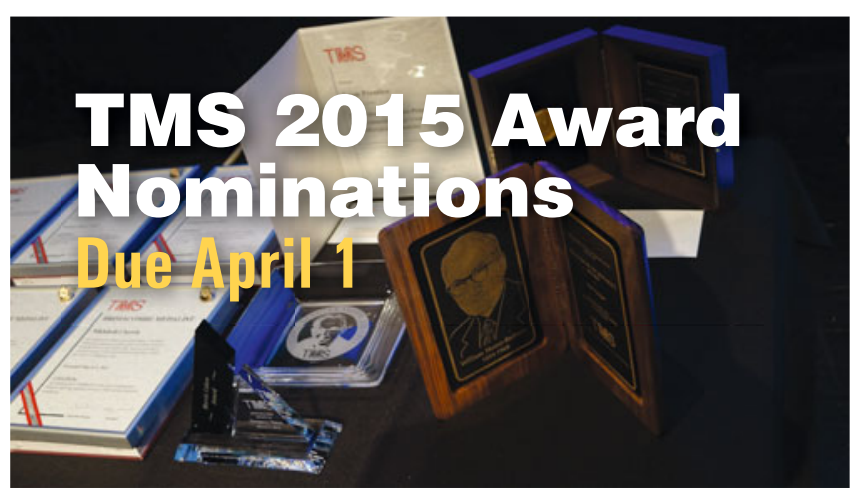

Nominating a colleague for a TMS award is a meaningful way of honoring someone who has made a significant impact on the minerals, metals, and materials professions through scholarship, leadership, or mentoring. While highlighting outstanding accomplishments of TMS members is an obvious goal, the TMS Honors and Awards Program also plays an integral role in advancing the society's mission. Many award winners share their knowledge through special lecture opportunities, while others receive support to enhance their professional development through conference participation. All benefit from being recognized before their peers, while also inspiring other scientists and engineers, at all phases of their careers, to strive for this same or higher level of excellence.

To begin the nomination process, visit the recently upgraded TMS Honors and Awards Program website at awards.tms.org. Criteria and submission information is provided for every TMS award, accessed from a drop down menu. Specific bylaws references, as well as a complete listing of current and past winners, are included. An online search capability makes it easy to find information, while the universal nomination form is readily accessible.

Go to awards.tms.org today and consider participating in the TMS Honors and Awards Program as a nominator, applicant, or awards committee member. For additional information, contact Deborah Price, TMS Awards and Recognition Specialist, at price@tms.org.

The deadline for submitting nominations for most awards to be conferred by TMS in 2015 is April 1 . 